\title{
Teaching Architectural Design Studio Remotely: The Introduction to Architectural Design Course at METU
}

\author{
Esin Komez Daglioglu (1) \\ Middle East Technical University, Faculty of Architecture, Ankara, Turkey (Corresponding author) \\ Ekin Pinar \\ Middle East Technical University, Faculty of Architecture, Ankara, Turkey \\ Ipek Gursel Dino 무 \\ Middle East Technical University, Faculty of Architecture, Ankara, Turkey \\ Pelin Yoncaci Arslan \\ Middle East Technical University, Faculty of Architecture, Ankara, Turkey \\ Funda Bas Butuner \\ Middle East Technical University, Faculty of Architecture, Ankara, Turkey
}

Received: November 3rd 2020, Accepted: November 11th 2020

Refer: Daglioglu Komez, E., Pinar, E., Gursel Dino, I., Yoncaci Arslan, P., Bas Butuner, F., (2020), Teaching Architectural Design Studio Remotely: The Introduction to Architectural Design Course at METU, Journal of Design Studio, V.2, N.2, pp 143-147,

E. Komez Daglioglu ORCID: 0000-0002-8598-6213, E. Pinar ORCID: 0000-0002-8367-1234, I. Gursel Dino ORCID: 0000-0003-22169192, P. Yoncaci Arslan ORCID: 0000-0003-3908-0653, F. Bas Butuner ORCID: 0000-0002-6203-9002, DOI: $10.46474 /$ jds.820352 https://doi.org/10.46474/jds.820352

\begin{abstract}
This paper aims to briefly assess the potentials and limits of online learning environment for studio education by focusing on the case of 2019-20 spring semester studio of Introduction to Architectural Design course at Middle East Technical University's Department of Architecture. As a transitory course between basic design principles and architectural design, Introduction to Architectural Design addresses the issues of site, program, structure, form, and material in reference to small scale architectural interventions. Reviewing the usual course of the semester until the COVID-19 outbreak as well as the effects of the unexpected switch to the emergency distance teaching, the paper highlights both the creative advantages and material shortcomings of the course's adaptation process into the online studio format.
\end{abstract}

Keywords: Architectural Design Studio, Exploratory Design Education, Emergency Distance Teaching

Introduction to Architectural Design course, given at the second semester of the first-year design studio at Middle East Technical University (METU) Department of Architecture, is a transitory course between the basic design studio of the first semester and the architectural design studios of the following years. It aims at developing the skills for rapport between basic design principles and architectural design. Therefore, it addresses the issues of site, program, structure, form, and material in reference to small scale architectural interventions. These objectives shaped the principles of three distinct yet interrelated assignments of the spring semester studio of 2019-20. In the first assignment titled "Bodyscapes," our main aim was to understand the relation between the body, movement and space. This assignment asked the students to position their body in physical relation to a specific land that they would choose from the METU Campus. Following the example of artist Dennis Oppenheim's work Parallel Stress, students photographically captured this 
moment highlighting the tension between the body and land. Afterwards, students were asked to design a vertical milieu that defines a flow of spaces, which accommodate the body postures captured and analyzed in the previous step. The second assignment titled "Eventscapes" intended to analyze and understand the relation between topography, event, and movement. In the scope of this assignment, students first observed and recorded the human movement, various uses, events and activities of a given site from the METU Campus during the course of a day as well as a week. They, then, developed an abstract map based on their site-reading, which they subsequently used as a diagram for rearticulating the topography of the assigned site.

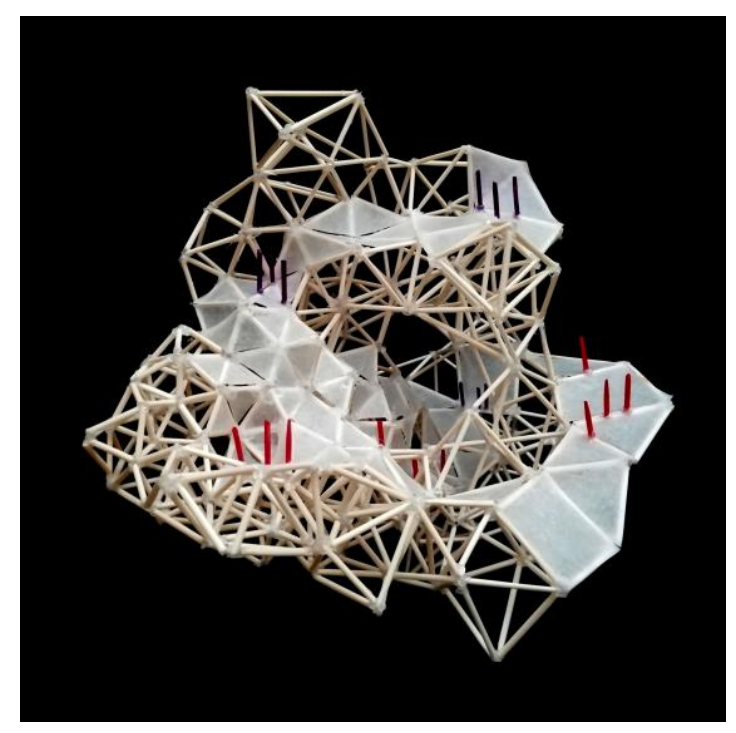

Figure 1. Dican Deniz Köse, Perform-a-scape, model technique: $3 D$ frame with wooden sticks

By the end of these two assignments, we switched to emergency distance education due to the global COVID-19 pandemic. This final assignment became our first experience in implementing studio education through online means. The final exercise titled "Perform-ascape" began with watching the movie Grand Budapest Hotel (2014) directed by Wes Anderson. We asked the students to pick three scenes from the film and analyze them by using plan, section, perspective, axonometric

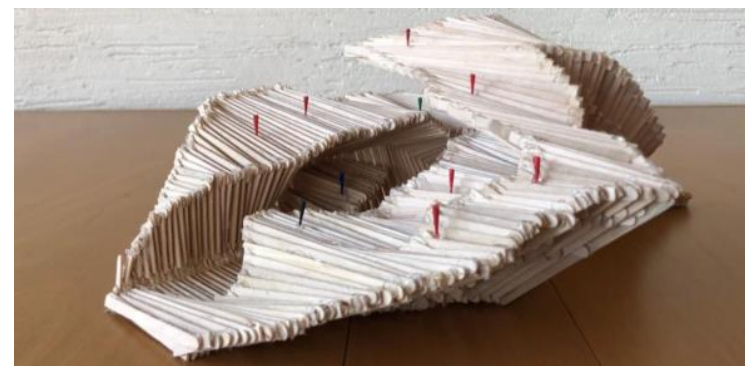

Figure 2. Nusret Atakan Harmancl, Perform-ascape, model technique: vertical sectioning with ice-cream sticks

drawings, photographs, or collages. These analytical drawings showed the characteristics (scale, indoor/outdoor, altitude, people density, color, light, enclosure degree, etc.) of each space represented within the scenes as well as the movement and interaction between them as

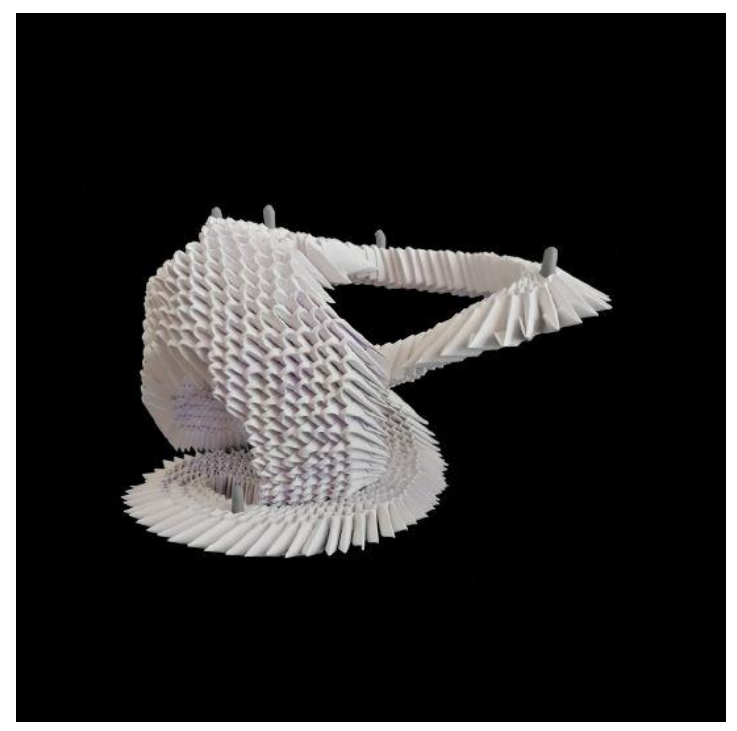

Figure 3. Betül Dinç, Perform-a-scape, model technique: aggregation with folded paper

the story unfolds. Following this analysis, we asked the students to design a perform-a-scape by transforming these scenes into three interrelated stages for a live performance of The Grand Budapest Hotel. This perform-a-scape was expected to conceptualize and accommodate these stages as well as the movement of the performers and the audience. During the digital desk crits, we emphasized that the final design should focus not on the set design of the stages but on the abstraction of their spatial aspects and positioning as well as 
their relation to the audience and to each other. These spatial aspects also had to take into account design considerations such as human scale, various degrees of enclosure, sequence, proportions, permeability, and accessibility. For the construction principles of the perform- $a$ scape, students used 3D frame, weaving, aggregation, or vertical sectioning. Some used readily available materials such as sugar cubes, pasta, matchboxes, etc. as their design units. Others generated units from newspapers, sketch papers, toilet paper rolls, etc. by applying operations such as folding, bending, twisting, or rolling. hours via online platforms. Thus, we engaged with the photographs and video clips of their projects instead of the physical models. A rather indirect, digitally enhanced visual involvement replaced the immediate tactile experience. In other words, the 'flattening' effect of the computer screen became part of our online studio life. Furthermore, the scarcity of the materials and limited access to stationaries led students to use daily objects such as staplers, clothespins and sugar cubes more creatively. Along with these unusual architectural models, students also used digital drawing tools more intensely in order to improve, test and present

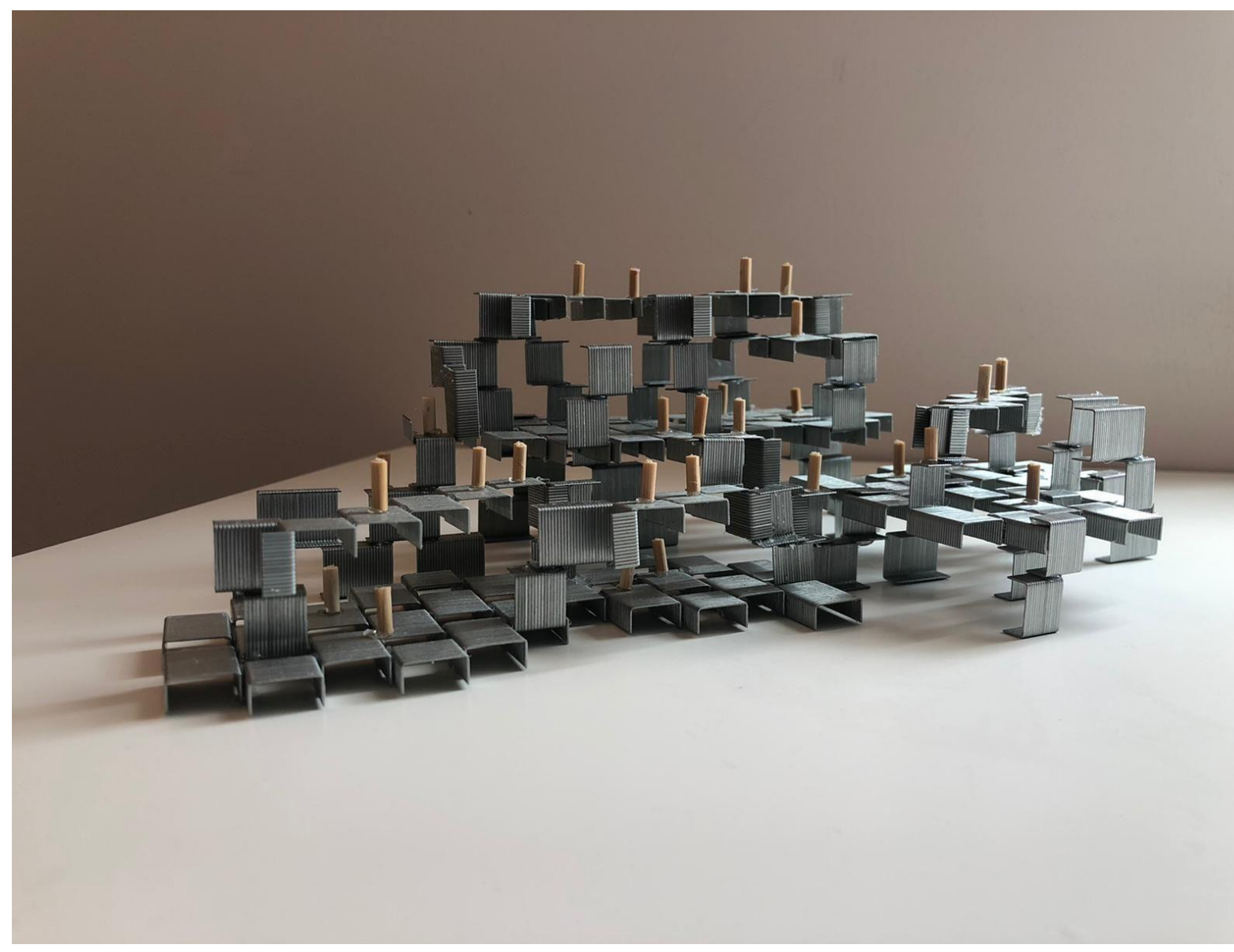

Figure 4. Sena Nur Cabadağ, Perform-a-scape, model technique: aggregation with staples

This final exercise was a great experiment for us to discover, test, and evaluate the potentials and limits of online learning environment for studio education. We continued to meet regularly with the students during the studio their design decisions and consequently most of them developed mature graphical communication skills faster than those of the previous years did. In conclusion, although the remote education cannot replace the direct 


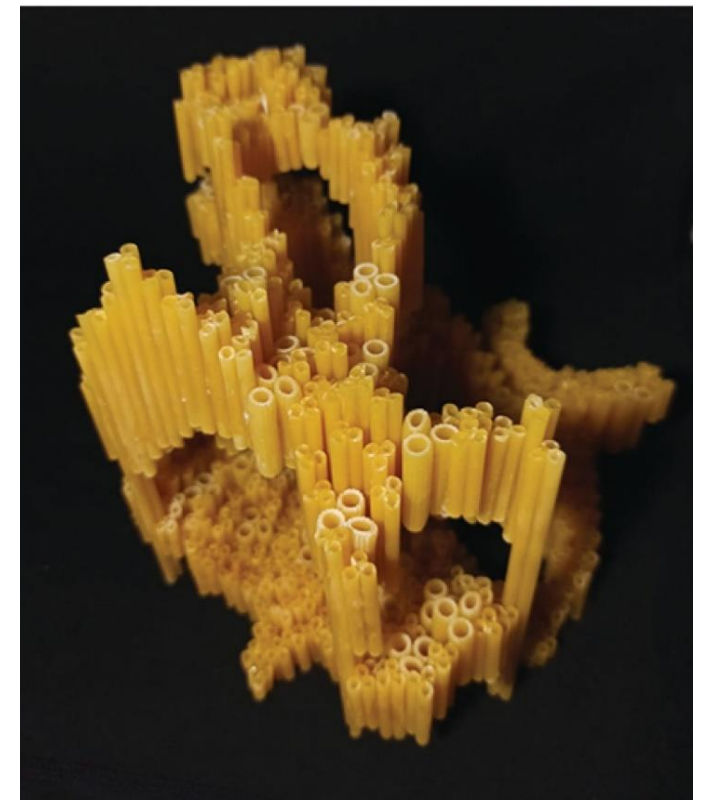

Figure 5. Suhenda Demir, Perform-a-scape, model technique: aggregation with pasta

physical interaction of the studio environment, the studio adapted to "the new normal" very quickly and established a new routine for online discussions and crits. Students continued without any substantial break by making good use of materials at their disposal in their homes. This resulted in a great diversity among the final models in terms of the variety of materials and model-making techniques. The final projects clearly demonstrate how the design skills of the students have developed in articulating the relation between form, program, structure, and material even when instructed remotely. The teaching methods and design pedagogies pursued in this particular case may provide a basis for other distance teaching and learning practices that aim to generate an interactive studio environment despite the limits posed by physical and social distance.

\section{Acknowledgments}

We would like to thank all our students for their hard work, our research assistants Zuhal Acar, Caner Arıkboğa, Elif Bekar, Ayça Duran, Beril

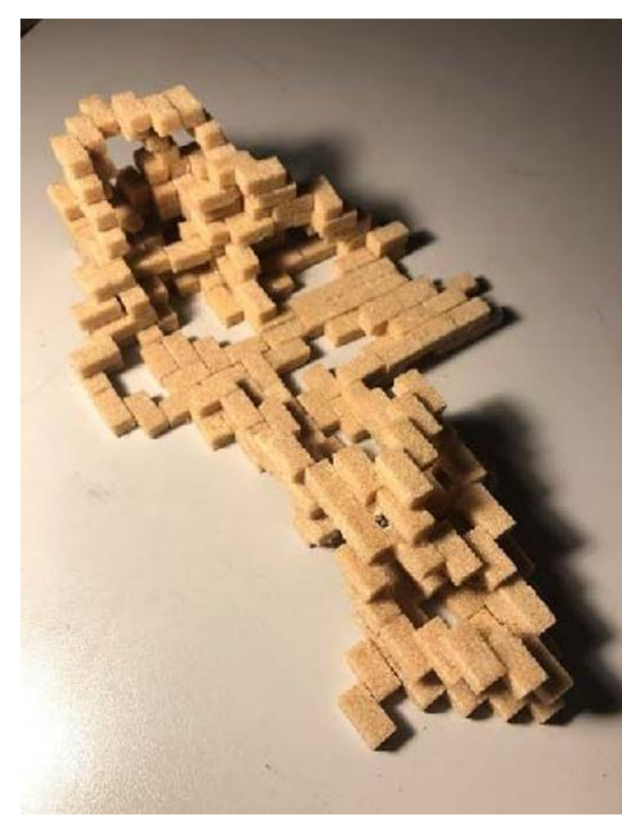

Figure 6. Meltem Şahin, Perform-a-scape, model technique: aggregation with sugarcubes

Önalan, Öncü Özalp and Duygu Simser for their contribution and our master teacher Şenol Yağız for her support.

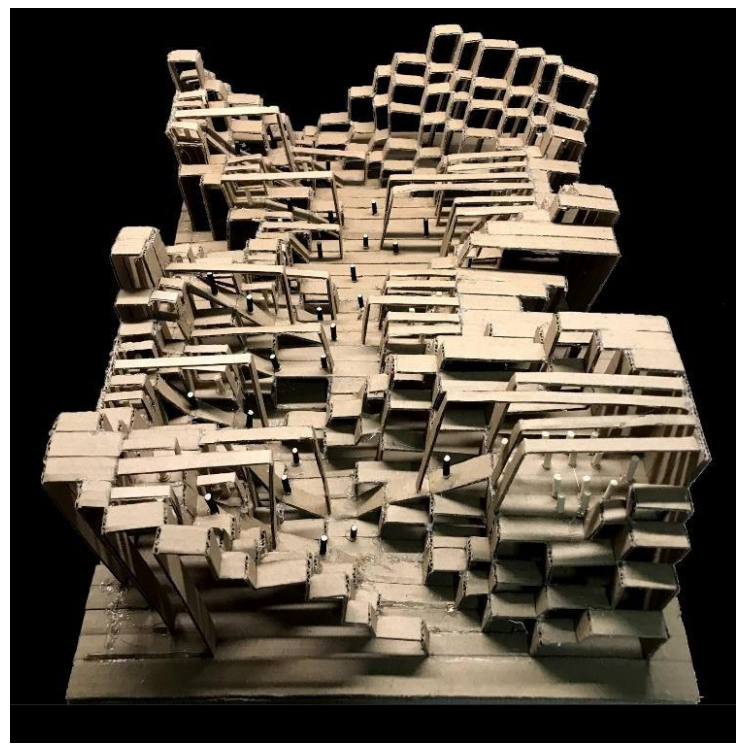

Figure 7. Moustafasamir Saada, Perform-a-scape, model technique: sectioning with cardboard 


\section{Journal of \\ Design Studio}

v:2 n:2 December 2020

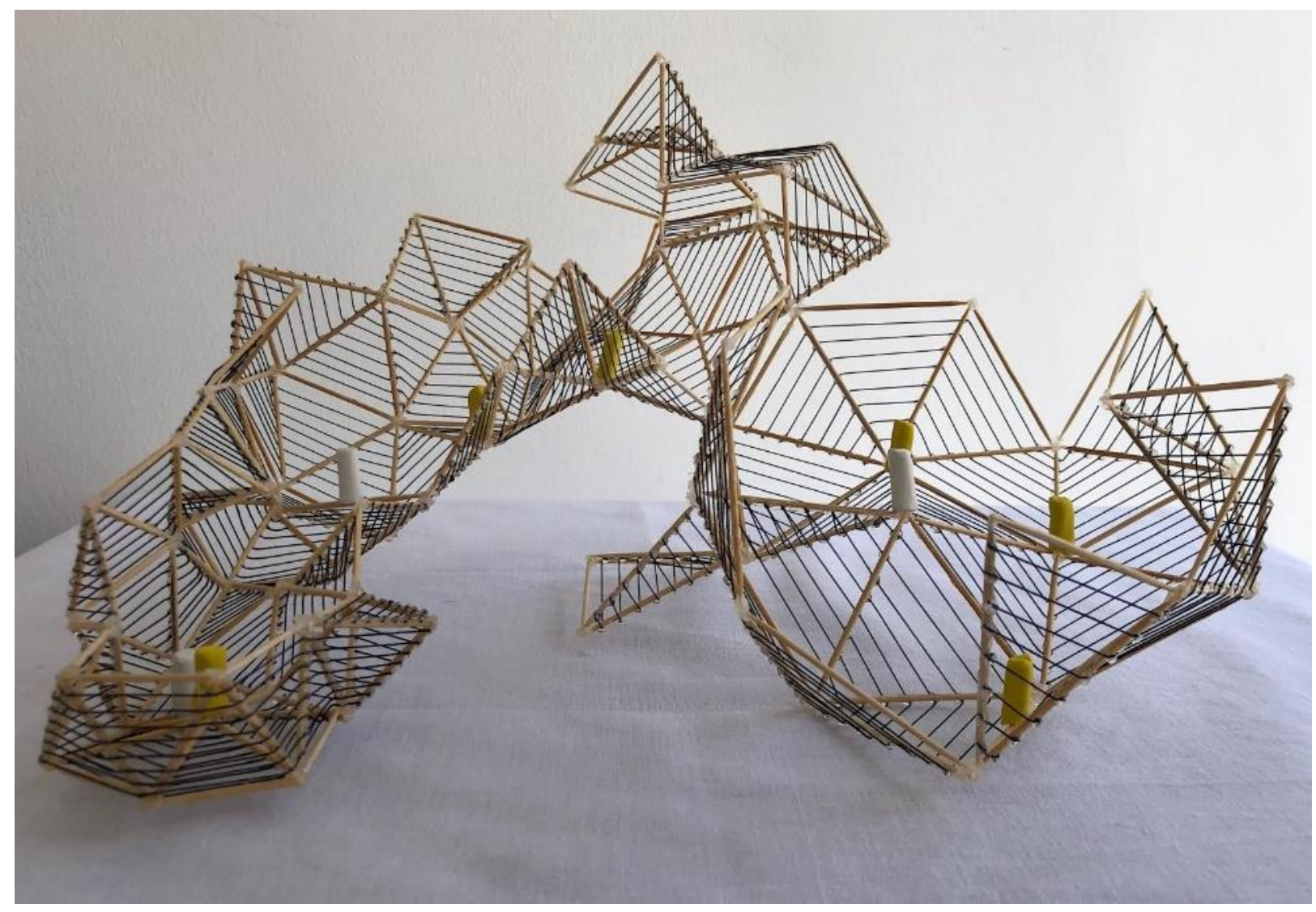

Figure 8. Zeynep Büşra Bekar, Perform-a-scape, model technique: weaving with wooden sticks and string 